\title{
Clinical application of DEX/CRH test and multi-channel NIRS in patients with depression
}

\author{
Shinya Kinoshita ${ }^{1}$, Tetsufumi Kanazawa ${ }^{1 *}$, Hiroki Kikuyama ${ }^{1,2}$ and Hiroshi Yoneda ${ }^{1}$
}

\begin{abstract}
Background: To reduce the number of patients with depression, biomarkers for clarifying psychiatric disorders are warranted. Numerous candidates have been proposed; however, near-infrared spectroscopy (NIRS) with multichannel probes and a dexamethasone/corticotropin-releasing hormone (DEX/CRH) test are still surviving for practical demand. Thirty-one outpatients with depressed moods were analyzed using both biological tests.

Results: The non-suppressors, as indicated by the DEX/CRH test, exhibited a high severity on the Hamilton Depression Scale and severe anxiety on the State Trait Anxiety Scale. In addition, a unique response was identified via NIRS in the same group suggested by the DEX/CRH assessment.

Conclusions: The results obtained from these biological tests did not fit well with the category defined by operative diagnostic criteria, such as the Diagnostic and Statistical Manual of Mental Disorders or The International Classification of Diseases. Thus, it is critical that the utility evaluations of candidate biomarkers not be assessed by comparisons with the categorized criteria for a specific psychiatric disorder.
\end{abstract}

Trial registration UMIN000013214, Registered 21 February 2014

Keywords: DEX/CRH test, NIRS, Depression, Biomarker, HAMD

\section{Background}

A depressed mental state is caused by non-specific mental disorders, such as a mood disorder, schizophrenia, substance abuse, a personality disorder, or nearly every psychiatric condition. If it is more prolonged than expected, several types of costs related to individuals with depressed moods will increase. A recent analysis indicated a $21.5 \%$ cost increment, $\$ 173.2$ billion (2005) to $\$ 210.5$ billion (2010), within 5 years, and this cost will be further increased [9]. Another analysis with regard to the global DALY (disability-adjusted life year) indicated that the cost associated with depression would represent the primary cost of all disorders, including physical disorders, in 2030, and it ranked 3rd in 2004 (http://www.who.int/healthinfo/global_burden_disease/

\footnotetext{
*Correspondence: psy052@osaka-med.ac.jp

1 Department of Neuropsychiatry, Osaka Medical College, 2-7,

Daigaku-Cho, Takatsuk, Osaka 569-8686, Japan

Full list of author information is available at the end of the article
}

GBD_report_2004update_part4.pdf). These analyses have provided warnings regarding the importance of depression prevention. In addition, to perform effective treatment, a precise assessment based on scientific data comprises a key factor.

Evidence regarding the relationship between depression severity and blood flow measurements scaled by Near-Infrared Spectroscopy (NIRS) is accumulating [30, $36,41]$. NIRS comprises a non-invasive imaging device that uses multiple channels to visualize brain activity. It has been developed as a result of the demand to consider a differential diagnosis in patients with depressed moods despite the administration of antidepressant agents for an extended period. A reliable biological marker is required to identify a specific psychiatric disorder because diagnosis in psychiatry currently relies on expressed symptoms or spoken words. NIRS comprises a device that applies knowledge of neuroscience through the assessment of blood flow in the brain; however, another 
potential candidate for a reliable biomarker depends on an endocrine imbalance. Particularly in the assessment of disturbed regulation of the hypothalamic-pituitaryadrenocortical (HPA) system, dexamethasone/corticotropin-releasing hormone (DEX/CRH) has been extensively investigated with a view towards the differential diagnosis of depression prior to the development of NIRS. Originally, the dexamethasone suppression test (DST) was used to diagnosis Cushing's syndrome [22]; this endocrine reaction has also been implemented for the diagnosis of endogenous depression. The current standard method is a DEX/CRH test in combination with the administration of $\mathrm{CRH}$, which has been reported to increase the sensitivity from 60 to $80 \%$ for the classic type of depression [12, 13]. There is an unavoidable burden regarding the application of this method for practical usage; however, these two biological methods have been considerably implemented in previous decades for investigating the biomarkers of depression.

In the current study, we investigated patients with a depressed mental state. Following a diagnosis according to the DSM-IV or psychological assessments, two tests using both endocrine (DEX/CRH) and neuroimaging (NIRS) assessments were applied. The aim of the current work was to identify the relationship between the psychiatric diagnosis based on the expressed symptoms and the assessment of two biomarkers.

\section{Methods}

\section{Subjects}

The subjects comprised 31 outpatients (15 men and 16 women; mean age: 44.2 years, SD: 12.2 years) with a depressive state, who were recruited from patients who attended the Neuropsychiatry Department of Osaka Medical College. The demographic details of the psychiatric diagnoses are shown in Table 1. We have adopted structured clinical interview for DSM-IV TR (SCID) for clinical assessment [7].

The severity of the index depressive episode was assessed with the 21-item version of the Hamilton depression rating scale (HAMD) [10, 15], on the admission day (DEX/CRH on the 2nd day and NIRS on the 3rd day). Enrolled patients $(n=31)$ were not strictly limited along with the HAMD score because all of the participants had the difficulty to live their life. Regarding the self-evaluation tool for anxiety, the STAI, the State-Trait Anxiety Inventory [26, 34], was administered to the participants on admission day. The majority of the patients were medicated with antidepressants; however, we did not control for the class of antidepressant medication. In addition, we assessed the psychiatric disorders of patients along with the SCID method; therefore, psychiatric comorbidities were not controlled.

\section{DEX/CRH test}

The DEX/CRH test was conducted according to the method described by Zobel et al. [42]. The subjects were pretreated with an oral dose of $1.5 \mathrm{mg}$ of DEX at $2200 \mathrm{~h}$ on the 1st admission day. On the next day, a vein was cannulated at $1400 \mathrm{~h}$ to collect blood at 1430, 1500, 1530, 1545 , and $1600 \mathrm{~h}$ via an intravenous catheter. Human $\mathrm{CRH}(100 \mu \mathrm{g})$ was intravenously administered at $1400 \mathrm{~h}$ immediately after the initial blood collection. The plasma concentrations of ACTH and cortisol were measured via radioimmunoassay at SRL Corporation (Tokyo, Japan). The detection limits for ACTH and cortisol were $5.0 \mathrm{pg} /$ $\mathrm{ml}$ and $1.0 \mu \mathrm{g} / \mathrm{dl}$, respectively.

The definition of the subtypes of the cortisol suppression pattern followed previously described criteria $[19,14]$ and included incomplete-suppressors (DEX/ CRH-cortisol $\geq 5 \mu \mathrm{g} / \mathrm{dl}$, moderate-suppressors $(1 \mu \mathrm{g} /$ $\mathrm{dl} \leq \mathrm{DEX} / \mathrm{CRH}$-cortisol $<5 \mu \mathrm{g} / \mathrm{dl}$ ), and enhanced-suppressors (DEX/CRH-cortisol $<1 \mu \mathrm{g} / \mathrm{dl})$. We also included a non-suppressor group with cortisol $>5 \mu \mathrm{g} / \mathrm{dl}$ at the test onset to reduce the number of incomplete suppressors (onset-cortisol $<5 \mu \mathrm{g} / \mathrm{dl}$ ).

\section{NIRS measurement}

The NIRS measurements were performed using a 22-channel ETG-4000 Optical Topography System (Hitachi Medical Corporation, Tokyo, Japan). This machine used two sets of wavelengths of near-infrared light (695 and $830 \mathrm{~nm}$, respectively) to identify differences in the absorption spectrum, which thus enabled the measurement of oxy-Hb and deoxy-Hb [23]. Seventeen emitter probes and 16 detector probes were plugged into a $3 \times 11$ array. The distance between the pair of emission and detector probes was $3.0 \mathrm{~cm}$; the measuring area between each pair of detector probes was defined as a "channel." Probes were placed on the frontal region of the participant. The lowest probes were positioned along the Fp1-Fp2 line in accordance with the international 10-20 system used in electroencephalography.

\section{Activation task}

Changes in the hemoglobin concentration were measured during the verbal fluency task [37]. The cognitive activation task was structured to include a 30 -s pretask period, a 60 -s task period, and a 70-s post-task period. For the pre- and post-task baseline periods, the participants were instructed to consecutively repeat five Japanese vowels (a, i, u, e, o) aloud. During the task periods, they were instructed to generate as many Japanese words as possible that began with a designated syllable. The initial syllables were presented in counterbalanced order among the participants with 


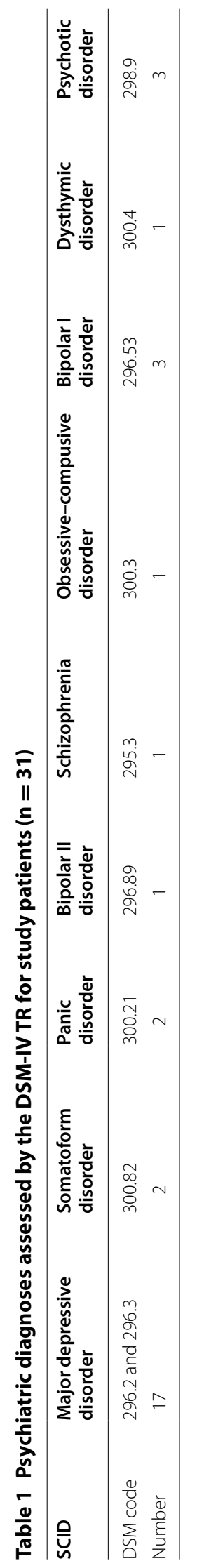


each syllable changing every $20 \mathrm{~s}(0-20 \mathrm{~s}: / \mathrm{to} /, / \mathrm{na} /$, /a/; 20-40 s:/se/, /i/, /ki/; 40-60 s: /o/, /ta/, /ha/) during the 60 -s task period.

\section{Measurement environment}

Each participant was seated in a comfortable chair and instructed to remain still to prevent movement artifacts; specifically, head movements, strong biting, or unnecessary eyebrow movements were minimized during the NIRS measurements. The data that clearly contained motion artifacts, based on both our observations and NIRS recordings, were excluded from further analyses.

\section{Statistical analysis}

All statistical analyses were performed with JMP Pro ${ }^{\circledR}$ software (Ver. 11.0, SAS Institute Japan Ltd., Tokyo, Japan). Intergroup comparisons were conducted for HAMD, STAI scores and the gained scores from NIRS instrument according to the Kruskal-Wallis test. A value of $p<0.05$ was considered statistically significant.

\section{Results}

According to the previously described criteria for the division of the DEX/CRH response, the numbers of participants in the four groups divided by the cortisol reaction are indicated in Table 2.

First, the association between the reaction in the DEX/ $\mathrm{CRH}$ test and the severity of depression determined by the HAMD assessment was investigated. The HAMD was recorded by another clinician in a blind manner. There was a difference in the mean value of the HAMD score between the non-suppressors and the other two main groups, incomplete suppressors and moderate suppressors (Fig. 1 Kruskal-Wallis analysis Chi square 7.37, $\mathrm{p}=0.06$ ). Second, the STAI, which is a self-evaluation tool for anxiety, significantly represented the characteristic psychological feature of the non-suppressor group compared with the other three groups (Fig. 2 KruskalWallis analysis Chi square 7.58, $\mathrm{p}=0.06$ ). Moreover, we compared the results of the NIRS assessment with the reaction of the DEX/CRH test. Similar to the HAMD assessment, the NIRS recording was performed by a lab technician in a blind manner. The results indicated that the values of the center of gravity at the frontal lobe in the non-suppressor group, which comprised the

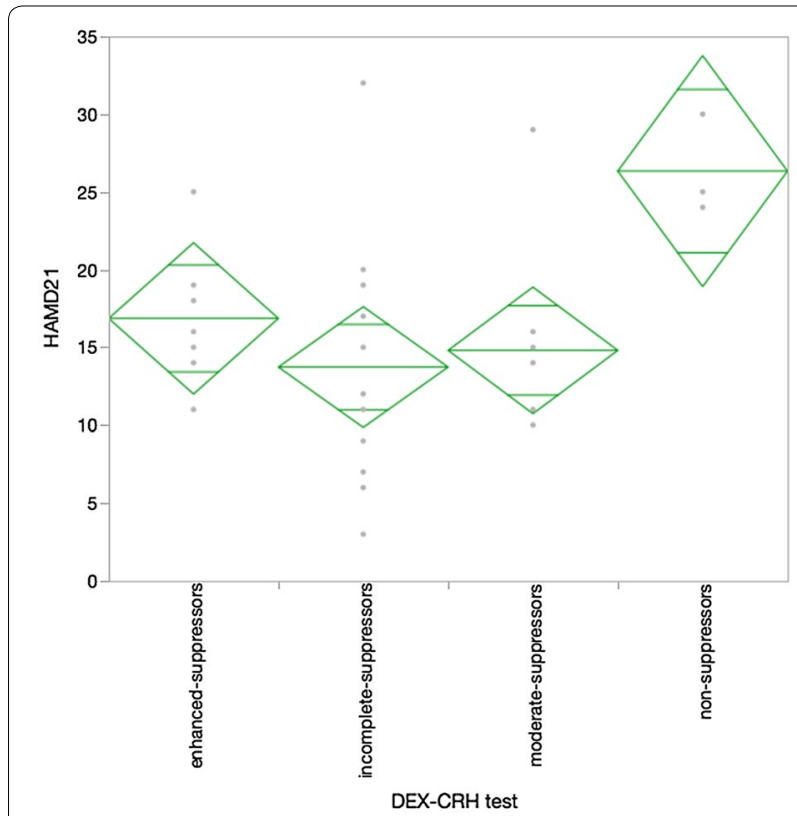

Fig. 1 Diamond plot of the HAMD 21 assessment and DEX-CRH test $(n=31)$. Kruskal-Wallis analysis Chi square 7.37, $p=0.06$. Post hoc analysis non-suppressors, $26.3 \pm 3.2$, vs incomplete suppressors, $13.7 \pm 8.2, p=0.04$, vs moderate suppressors, $14.8 \pm 5.8, p=0.03$

representative values in NIRS, were significantly different compared with the other three groups by post hoc analysis (Fig. 3 Kruskal-Wallis analysis Chi square 7.02, $p=0.07)$. No significant age difference between the groups that were defined by the two biological methods was found (data not shown).

\section{Discussion}

The current sample size is relatively small to provide a definitive conclusion; however, our current work has an advantage in which we employed cases regardless of the diagnosis of psychiatric disorders. Therefore, there is the potential that the novel scientific findings identified from our sample are consistent across diagnoses based on the operative diagnostic criteria, such as the DSM. In addition, this is the first report to assess confirmed cases with depressed mood by two representative assessment methods for depression.

Regarding the DEX/CRH test, it has been reported that $60-80 \%$ of patients with depression exhibited an

Table 2 Number of patients with depression divided by the DEX/CRH test $(n=31)$

\begin{tabular}{lllcr}
\hline & DEX/CRH-cortisol & Onset cortisol & Male & Total \\
\hline Enhanced-suppressors & $<1 \mu \mathrm{g} / \mathrm{dl}$ & & 2 \\
Moderate-suppressors & $1 \mu \mathrm{g} / \mathrm{dl} \leq<5 \mu \mathrm{g} / \mathrm{dl}$ & & 5 \\
Incomplete-suppressors & $\geq 5 \mu \mathrm{g} / \mathrm{dl}$ & Onset cortisol $<5 \mu \mathrm{g} / \mathrm{dl}$ & 2 & 8 \\
Non-suppressors & $\geq 5 \mu \mathrm{g} / \mathrm{dl}$ & Onset cortisol $\geq 5 \mu \mathrm{g} / \mathrm{dl}$ & 3 & 3 \\
\hline
\end{tabular}




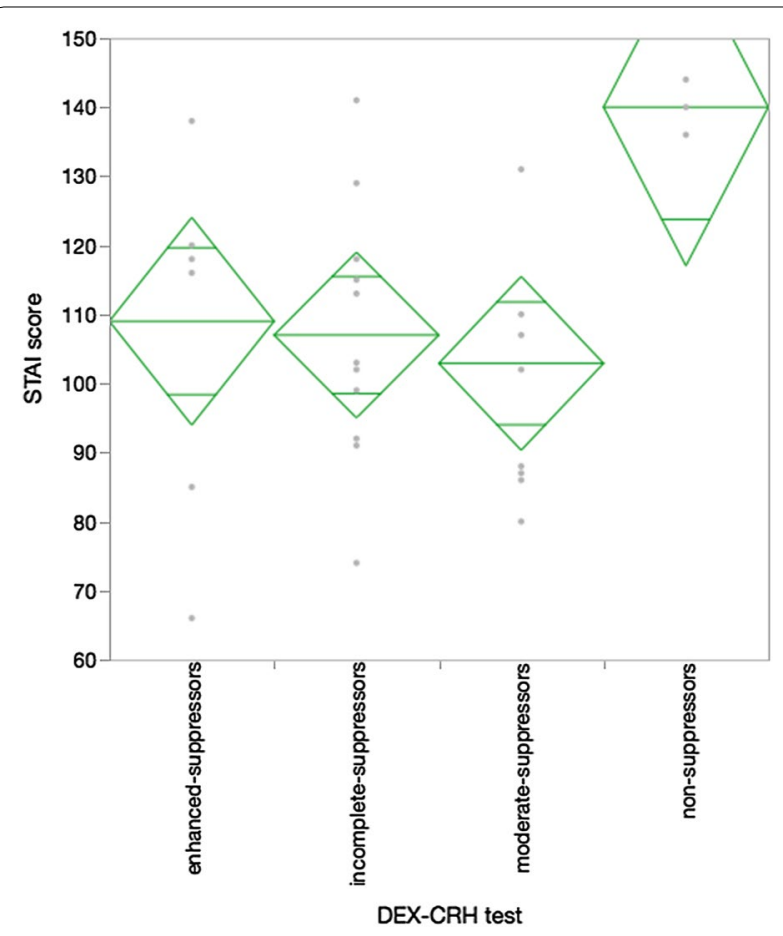

Fig. 2 Diamond plot of the STAI assessment and DEX-CRH test $(n=31)$. Kruskal-Wallis analysis Chi square 7.58, $p=0.06$. Post hoc analysis non-suppressors, $140 \pm 4.0$, vs incomplete suppressors, $107 \pm 18.8, p=0.03$, vs moderate suppressors, $103 \pm 18.1, p=0.01$ vs enhanced suppressors, $109 \pm 24.6, p=0.04$

increased cortisol response prior to the initiation of treatment $[18,42]$. It is partly because all participants in this study received medical treatment prior to the assessment, whereas only $11 \%(3 / 31)$ of the participants in this study exhibited an increase cortisol response (non-suppressors). Moreover, most previous studies utilizing DEX/CRH test have been based on data obtained from inpatients [18, 20], which implies a clinical subgroup with severe symptoms, whereas our current sample consisted of a depression severity at the outpatient level. Moreover, the group that enrolled the largest sample size did not include data for individuals with a HAMD less than 15 [18], whereas the average HAMD score was $15.6 \pm 7.5$ in our sample. This difference has a significant impact on the interpretation of our data. The percentage of non-suppressors was not high because of the enrolled mild subtype of depression; however, every non-suppressor patient exhibited a high score on the HAMD assessment (average score of HAMD: 27.8) despite inconsistencies in the psychiatric disorders across three patients (two patients: 296.23 major depressive disorder, and one patient: 300.3 obsessive compulsive disorder). Thus, the DEX/CRH approach should again be considered a potentially useful biomarker for dividing the subclasses of depression.

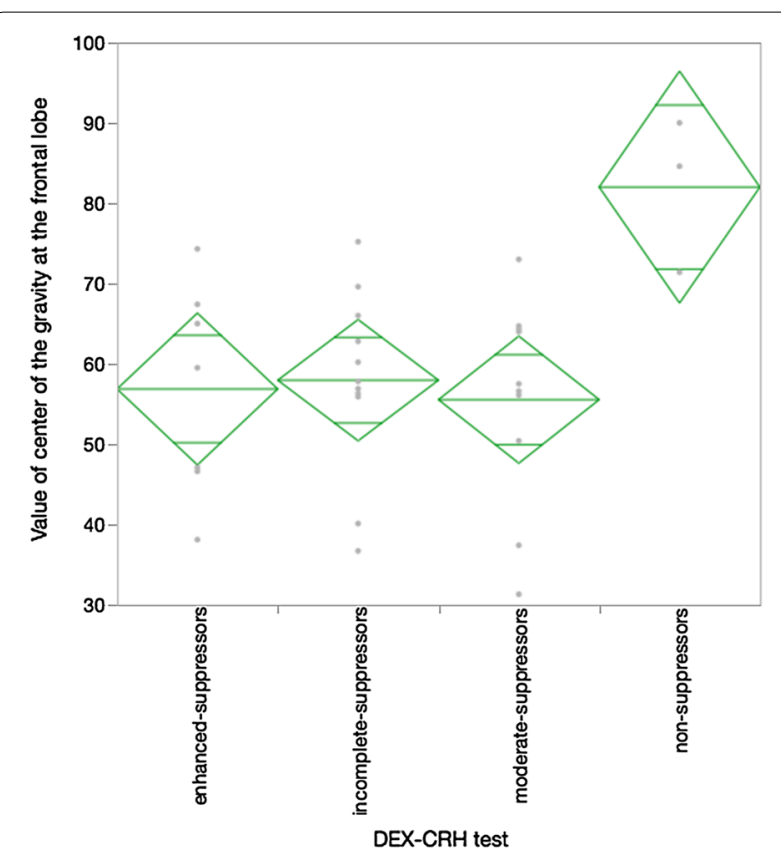

Fig. 3 Diamond plot of the NIRS assessment (value of the center of gravity at the frontal lobe) and DEX-CRH test $(n=31)$. Kruskal-Wallis analysis Chi square 7.02, $p=0.07$. Post hoc analysis non-suppressors, $82.0 \pm 9.6$, vs incomplete suppressors, $58.0 \pm 11.4, p=0.02$, vs moderate suppressors, $55.5 \pm 12.8, p=0.02$, vs enhanced suppressors, $56.9 \pm 13.2, p=0.04$

With regard to psychological aspects assessed by STAI, the Kruskal-Wallis analysis indicated there was no significant difference for the divided subgroups regarding the DEX/CRH test; however, a trend was identified particularly for the non-suppressor group (Chi square $7.58, \mathrm{p}=0.06$ ). Anxiety is a non-specific feature of psychiatric disorders. Therefore, the severity of anxiety is not fundamentally considered to be scaled by a biological method. Although the scale is simply based on a self-evaluation scale, our results indicated the potential finding that anxiety across psychiatric disorders, including depression, is represented by a biological scale, such as DEX/CRH. Anxiety-related stimuli cause a systemic response through neural circuits centered on the amygdala, which enhances the increment of cortisol [38]. Therefore, an association between the altered DEX/CRH result and the anxiety scale is reasonable. A previous study demonstrated that individuals with depression and comorbid anxiety $(\mathrm{n}=18)$ related disorders exhibited a significantly lower cortisol level compared with pure depression patients $(\mathrm{n}=36)$ [40]. The non-suppressor group, which showed higher anxiety, more severe depressive symptoms and a distinguished response in the DEX/ $\mathrm{CRH}$, should be regarded as one entity in terms of different biological and psychological reactions. Thus, larger 
sample sizes, especially for the non-suppressor group, are necessary to clarify the association between the STAI scale and DEX/CRH results.

Accumulating evidence supports the relationship between NIRS and the diagnosis of psychiatric disorders $[21,24,36]$. Thus, NIRS is one of the most attractive tools for adopting a biological assessment for clinical practice. One reason is that the device requires only 10-15 min for each individual if VFT is adopted for the assessment. NIRS is sufficiently easy to adopt, even for adolescents, for the evaluation of psychiatric disorders, such as depression, bipolar disorder, and schizophrenia. General interpretation on VFT is a neurocognitive battery for assessing verbal ability or executive control ability. This battery is widely used for assessing these abilities of patients after stroke, patients with Alzheimer's disease or Parkinson's disease [33]. In the current study, we have utilized this battery mainly for recording the measurements of oxy- $\mathrm{Hb}$ in the brain, therefore the task performance (the number of words) on each individual were not recorded. The comparison of the performance on VFT between each groups will be of interest. Future work should focus on the task performance across various psychiatric disorders. One of the critical issues regarding the NIRS device is that insufficient data are obtained from the perspective of neuroscience. In an analysis of a larger sample than the current work, our group recently demonstrated that the severity of depression scaled by the HAMD was negatively associated with the integral value of the blood flow at the frontal lobe $(n=43)$ [16]. This finding was characterized by the point that the assessment was not limited to depressed patients who satisfied the criteria defined by the DSM or ICD. Moreover, several biomarkers, such as DEX/CRH, NIRS and other factors, cannot guarantee the specificity of psychiatric disorders defined by operational diagnostic criteria. The current findings indicated that individuals with a Non-Suppression reaction in the DEX/CRH test exhibited a fairly increased value of the center of gravity at the frontal lobe. A general interpretation regarding the increased value of the center of gravity implies the existence of bipolarity [36]. In specific areas such as the left inferior frontal lobe, [oxy- $\mathrm{Hb}$ ] was decreased in patients with panic disorders $[27,28]$. Although the current work did not focus on a specific channel of NIRS, future research should analyze the data for a specific channel by assessing a larger sample series. Thus, a larger sample size is critical to validate the current work to determine the unknown mechanism of endocrine imbalance and brain response. In addition, the biological data from the mentally healthy controls will serve as a useful reference, although the current design has not been adopted to collect them. Moreover, the length of the duration of mental illness has a possible effect on the result from the biological assessment. This should be considered in future studies.

Biological assessments embedded in the diagnosis of specific psychiatric disorders are proceeding. Candidate methods have been evaluated using the concordance rate for diagnosis defined by the operative criteria to date; however, a universally accepted biomarker has not been identified. Despite substantial efforts to identify a biological marker, the methodological approach for objective evaluation is incorrect in terms of the fact that the concordance rate between biological assessments and psychiatric diagnoses based on the artificial operative system is not sufficient to satisfy practical demands. For example, a genetic approach has indicated considerable overlap between schizophrenia and bipolar disorder [6, 29]; therefore, the current understanding regarding these disorders has been modified to indicate that the two disorders are related diseases in terms of the genetic aspects [31]. Moreover, recent reports have indicated considerable genetic overlap across several types of psychiatric disorders $[4,8,11,25]$. According to a recent perspective based on genetic analyses, Craddock and his group have advocated the theory that psychiatric disorders are considered a spectrum [3]. It is true that a decreased frontal lobe is present in the brains of individuals with schizophrenia and bipolar disorder, as well as depression [5, 35]. Regarding therapeutic agents, antidepressants are effective for the improvement of symptoms in schizophrenia and bipolar disorders [32, 39]. Alternatively, antipsychotic agents are used for the treatment of depression [2]. Based on the traditional diagnostic category, it is impossible to explain the differences between psychiatric disorders by genetic or morphological factors or the responsiveness to therapeutic drugs. Our current finding indicates a trend of correlation between the severity of depression and the response to the DEX/CRH test; however, the diagnostic categories did not sufficiently fit the biological assessment. Moreover, our findings also suggest that the current diagnostic criteria are not valid for the assessment of biological markers in psychiatric disorders. Thus, the diagnostic criteria must be updated based on the contributions of biological assessments, such as DEX/CRH or NIRS $[1,17]$.

\footnotetext{
Abbreviations

DEX/CRH: dexamethasone/corticotropin-releasing hormone; NIRS: nearinfrared spectroscopy; ACTH: adrenocorticotropic hormone; HAMD: Hamilton rating scale for depression; STAl: state-trait anxiety inventory.

\section{Authors' contributions}

SK carried out the DEX/CRH test and drafted the manuscript. TK designed the study especially for NIRS and revised the manuscript. HK performed the statistical analysis. YH participated in the design of the study and conducted the study. All authors read and approved the final manuscript.
} 


\section{Author details}

${ }^{1}$ Department of Neuropsychiatry, Osaka Medical College, 2-7, Daigaku-Cho, Takatsuk, Osaka 569-8686, Japan. ${ }^{2}$ Department of Psychiatry, Shin-Abuyama Hospital, Osaka Institute of Clinical Psychiatry, Osaka, Japan.

\section{Acknowledgements}

We are grateful to Drs. Makoto Kawano, Masaki Nishiguchi, Yasuo Kawabata, Shigeru Yamauchi, Hiroyuki Uenishi, Seiya Kawashige, Shinichi Imazu, Katsunori Toyoda, Yoshitaka Nishizawa, Mayuko Takahashi, Tatsushi Okayama, Wakako Odo, Kentaro Ide, Soichiro Maruyama, Seiichiro Tarutani, Emi Minami Ryosuke Katsura, Yuko Higa, Tomoyoshi Nakano, Yoichiro Kubo, Shota Ouchi, and Tetsuya Togashi for helpful effort to collect the samples. We would like to thank Drs. Nanako Saito, Mai Yoshikawa, and other clinical psychotherapists for collecting the psychological data. We would like to thank Drs. Atsushi Tsutsumi and Jun Koh for the helpful discussion.

\section{Competing interests}

The authors declare that they have no competing interests.

\section{Availability of data and materials}

Anonymized raw data can be provided if it is needed.

\section{Ethics approval and consent to participate}

This study was approved by the ethical committee at Osaka Medical College. All of the participants have provided the written informed consent after the explanation of the study design. This clinical investigation was also approved and registered in the National registration system in Japan (UMIN000013214).

\section{Funding}

The funding of this research was provided by the department of Neuropsy chiatry, Osaka Medical College. No official grant was not used for this work.

Received: 5 May 2016 Accepted: 20 August 2016

Published online: 31 August 2016

\section{References}

1. Adam D. Mental health: on the spectrum. Nature. 2013:496:416-8.

2. Berman RM, Fava M, Thase ME, Trivedi MH, Swanink R, Mcquade RD, Carson WH, Adson D, Taylor L, Hazel J, Marcus RN. Aripiprazole augmentation in major depressive disorder: a double-blind, placebo-controlled study in patients with inadequate response to antidepressants. CNS Spectr. 2009:14:197-206

3. Craddock N, Owen MJ. The Kraepelinian dichotomy — going, going... but still not gone. Br J Psychiatr. 2010;196:92-5

4. de Rubeis S, He X, Goldberg AP, Poultney CS, Samocha K, Cicek AE, Kou Y, et al. Synaptic, transcriptional and chromatin genes disrupted in autism. Nature. 2014;515:209-15.

5. Drevets WC, Price JL, Simpson JR, Todd RD, Reich T, Vannier M, Raichle ME. Subgenual prefrontal cortex abnormalities in mood disorders. Nature. 1997;386:824-7.

6. Ferreira MA, O'Donovan MC, Meng YA, Jones IR, Ruderfer DM, Jones L, Fan $J$, et al. Collaborative genome-wide association analysis supports a role for ANK3 and CACNA1C in bipolar disorder. Nat Genet. 2008:40:1056-8.

7. First MB, Spitzer RL, Williams JBW, Gibbon M. Structured clinical interview for DSM-IV-TR (SCID-I)-research version. New York: Biometrics Research, New York State Psychiatric Institute; 2002.

8. Green EK, Grozeva D, Jones I, Jones L, Kirov G, Caesar S, Gordon-smith $\mathrm{K}$, et al. The bipolar disorder risk allele at CACNA1C also confers risk of recurrent major depression and of schizophrenia. Mol Psychiatr. 2010;15:1016-22.

9. Greenberg PE, Fournier AA, Sisitsky T, Pike CT, Kessler RC. The economic burden of adults with major depressive disorder in the United States (2005 and 2010). J Clin Psychiatr. 2015;76(2):155-62.

10. Hamilton M. A rating scale for depression. J Neurol Neurosurg Psychiatr. 1960;23:56

11. Han K, Holder JLJR, Schaaf CP, Lu H, Chen H, Kang H, Tang J, et al. SHANK3 overexpression causes manic-like behaviour with unique pharmacogenetic properties. Nature. 2013:503:72-7.
12. Heuser I, Yassouridis A, Holsboer F. The combined dexamethasone/CRH test: a refined laboratory test for psychiatric disorders. J Psychiatr Res. 1994:28:341-56.

13. Heuser IJ, Schweiger U, Gotthardt U, Schmider J, Lammers CH, Dettling $M$, Yassouridis A, Holsboer F. Pituitary-adrenal-system regulation and psychopathology during amitriptyline treatment in elderly depressed patients and normal comparison subjects. Am J Psychiatr. 1996;153:93-9.

14. Hori H, Ozeki Y, Teraishi T, Matsuo J, Kawamoto Y, Kinoshita Y, Suto S, Terada S, Higuchi T, Kunugi H. Relationships between psychological distress, coping styles, and HPA axis reactivity in healthy adults. J Psychiat Res. 2010;44:865-73.

15. Kalali A, Williams JBW, Kobak KA, Lipschitz J, Engelhardt N, Evans K, Olin J, Rotheman P, Bech P. The new GRID HAM-D: pilot testing and international field trials. Int J Neuropsychopharmacol. 2002;5:S147.

16. Kawano M, Kanazawa T, Kikuyama H, Tsutsumi A, Kinoshita S, Kawabata Y, Yamauchi S, et al. Correlation between frontal lobe oxy-hemoglobin and severity of depression assessed using near-infrared spectroscopy. J Affect Disord. 2016;205:154-8.

17. Koike S, Takizawa R, Nishimura Y, Takano Y, Takayanagi Y, Kinou M, Araki T, Harima H, Fukuda M, Okazaki Y, Kasai K. Different hemodynamic response patterns in the prefrontal cortical sub-regions according to the clinical stages of psychosis. Schizophr Res. 2011;132:54-61.

18. Kunugi H, Ida I, Owashi T, Kimura M, Inoue Y, Nakagawa S, et al. Assessment of the dexamethasone/CRH test as a state-dependent marker for hypothalamic-pituitary-adrenal (HPA) axis abnormalities in major depressive episode: a Multicenter Study. Neuropsychopharmacology. 2006;31:212-20.

19. Kunugi $H$, Urushibara T, Nanko S. Combined DEX/CRH test among Japanese patients with major depression. J Psychiatr Res. 2004:38:123-8.

20. Kunzel HE, Binder EB, Nickel T, Ising M, Fuchs B, Majer M, Pfennig A, Ernst G, Kern N, Schmid DA, Uhr M, Holsboer F, Modell S. Pharmacological and nonpharmacological factors influencing hypothalamicpituitary-adrenocortical axis reactivity in acutely depressed psychiatric in-patients, measured by the Dex-CRH test. Neuropsychopharmacology. 2003;28:2169-78.

21. Liu X, Sun G, Zhang X, Xu B, Shen C, Shi L, Ma X, Ren X, Feng K, Liu P. Relationship between the prefrontal function and the severity of the emotional symptoms during a verbal fluency task in patients with major depressive disorder: a multi-channel NIRS study. Prog Neuropsychopharmacol Biol Psychiatr. 2014:54:114-21.

22. Lodish M, Stratakis CA. A genetic and molecular update on adrenocortical causes of Cushing syndrome. Nat Rev Endocrinol. 2016;12:255-62.

23. Maki A, Yamashita Y, Ito Y, Watanabe E, Mayanagi Y, Koizumi H. Spatial and temporal analysis of human motor activity using noninvasive NIR topography. Med Phys. 1995;22:1997-2005.

24. Matsubara T, Matsuo K, Nakashima M, Nakano M, Harada K, Watanuki T, Egashira K, Watanabe Y. Prefrontal activation in response to emotional words in patients with bipolar disorder and major depressive disorder. Neuroimage. 2014;85(Pt 1):489-97.

25. Mccarthy SE, Gillis J, Kramer M, Lihm J, Yoon S, Berstein Y, Mistry M, et al. De novo mutations in schizophrenia implicate chromatin remodeling and support a genetic overlap with autism and intellectual disability. Mol Psychiatr. 2014:19:652-8.

26. Nakazato K, Mizuguchi T. Development and validation of Japanese version of state-trait anxiety inventory. Shinshin-Igaku. 1982:22:107-12.

27. NishimuraY Tanii H, Hara N, Inoue K, Kaiya H, Nishida A, Okada M, Okazaki Y. Relationship between the prefrontal function during a cognitive task and the severity of the symptoms in patients with panic disorder: a multichannel NIRS study. Psychiatr Res. 2009;172(2):168-72.

28. Nishimura Y, Tanii H, Fukuda M, Kajiki N, Inoue K, Kaiya H, Nishida A, Okada M, Okazaki Y. Frontal dysfunction during a cognitive task in drug-naive patients with panic disorder as investigated by multi-channel near-infrared spectroscopy imaging. Neurosci Res. 2007;59(1):107-12.

29. O'Donovan MC, Craddock N, Norton N, Williams H, Peirce T, Moskvina $V$, Nikolov I, et al. Identification of loci associated with schizophrenia by genome-wide association and follow-up. Nat Genet. 2008:40:1053-5.

30. Pu S, Nakagome K, Yamada T, Yokoyama K, Matsumura H, Yamada S, Sugie T, Miura A, Mitani H, Iwata M, Nagata I, Kaneko K. Suicidal ideation is associated with reduced prefrontal activation during a verbal fluency task in patients with major depressive disorder. J Affect Disord. 2015;181:9-17. 
31. Purcell SM, Wray NR, Stone JL, Visscher PM, O'Donovan MC, Sullivan PF, Sklar P. Common polygenic variation contributes to risk of schizophrenia and bipolar disorder. Nature. 2009;460:748-52.

32. Saito M, Yasui-furukori N, Nakagami T, Furukori H, Kaneko S. Dosedependent interaction of paroxetine with risperidone in schizophrenic patients. J Clin Psychopharmacol. 2005;25:527-32.

33. Shao Z, Janse E, Visser K, Meyer AS. What do verbal fluency tasks measure? Predictors of verbal fluency performance in older adults. Front Psychol. 2014;5:772.

34. Spielberger CD. Manual for the state-trait anxiety inventory STAI (form Y) (" self-evaluation questionnaire"): 1983

35. Stip E, Mancini-marie A, Letourneau G, Fahim C, Mensour B, Crivello F, Dollfus S. Increased grey matter densities in schizophrenia patients with negative symptoms after treatment with quetiapine: a voxel-based morphometry study. Int Clin Psychopharmacol. 2009;24:34-41.

36. Takizawa R, Fukuda M, Kawasaki S, Kasai K, Mimura M, Pu S, Noda T, et al. Neuroimaging-aided differential diagnosis of the depressive state. Neuroimage. 2014;85(Pt 1):498-507.
37. Takizawa R, Kasai K, Kawakubo Y, Marumo K, Kawasaki S, Yamasue H, Fukuda M. Reduced frontopolar activation during verbal fluency task in schizophrenia: a multi-channel near-infrared spectroscopy study. Schizophr Res. 2008;99:250-62.

38. Teicher MH. Biology of anxiety. Med Clin North Am. 1988;72:791-814.

39. Tohen M, Vieta E, Calabrese J, Ketter TA, Sachs G, Bowden C, Mitchell PB, et al. Efficacy of olanzapine and olanzapine-fluoxetine combination in the treatment of bipolar I depression. Arch Gen Psychiatr. 2003;60:1079-88.

40. Veen G, Derijk RH, Giltay EJ, van Vliet IM, Van Pelt J, Zitman FG. The influence of psychiatric comorbidity on the dexamethasone/CRH test in major depression. Eur Neuropsychopharmacol. 2009;19:409-15.

41. Zhang H, Dong W, Dang W, Quan W, Tian J, Chen R, Zhan S, Yu X. Nearinfrared spectroscopy for examination of prefrontal activation during cognitive tasks in patients with major depressive disorder: a meta-analysis of observational studies. Psychiatr Clin Neurosci. 2015;69:22-33.

42. Zobel AW, Nickel T, Sonntag A, Uhr M, Holsboer F, Ising M. Cortisol response in the combined dexamethasone/CRH test as predictor of relapse in patients with remitted depression. a prospective study. J Psychiatr Res. 2001;35:83-94.

\section{Submit your next manuscript to BioMed Central and we will help you at every step:}

- We accept pre-submission inquiries

- Our selector tool helps you to find the most relevant journal

- We provide round the clock customer support

- Convenient online submission

- Thorough peer review

- Inclusion in PubMed and all major indexing services

- Maximum visibility for your research

Submit your manuscript at www.biomedcentral com/submit 